\title{
Zs Research Square o \\ Prehabilitation to Improve outcomes afteR Autologous sTem cEll transplantation (PIRATE): A pilot randomised controlled trial protocol
}

Amy M Dennett ( $\sim$ amy.dennett@easternhealth.org.au )

Eastern Health https://orcid.org/0000-0002-4690-7949

Judi Porter

Deakin University

Stephen B Ting

Eastern Health

Nicholas F Taylor

La Trobe University - Bundoora Campus: La Trobe University

\section{Study Protocol}

Keywords: Prehabilitation, exercise, nutrition, supportive care, cancer, multiple myeloma, lymphoma, leukaemia

Posted Date: September 25th, 2020

DOI: https://doi.org/10.21203/rs.3.rs-82144/v1

License: (c) (i) This work is licensed under a Creative Commons Attribution 4.0 International License. Read Full License 


\section{Abstract}

Background

Autologous stem cell transplant is a common procedure for people with haematological malignancies. While effective at improving survival, autologous stem cell transplant recipients may have a lengthy hospital admission and experience debilitating side-effects such as fatigue, pain and deconditioning that may prolong recovery. Prehabilitation comprising exercise and nutrition intervention before stem cell transplant aims to optimise physical capacity before the procedure to enhance functional recovery after transplant. However, few studies have evaluated prehabilitation in this setting. We aim to determine preliminary efficacy of improving physical capacity of prehabilitation for people undergoing autologous stem cell transplant.

Methods

The PIRATE study is a single-blinded, parallel two-armed pilot randomised trial of multidisciplinary prehabilitation delivered prior to autologous stem cell transplantation. Twenty-two patients with haematological malignancy waitlisted for transplant will be recruited from a tertiary haematology unit. The intervention will include up to 8 weeks of twice-weekly, in-person, supervised tailored exercise and fortnightly nutrition education delivered via phone, in the lead up to autologous stem cell transplant. Blinded assessments will be completed at week 13, approximately 4 weeks after transplant and health service measures collected at week 25 approximately 12 weeks after transplant. The primary outcome is to assess changes in physical capacity using the 6-minute walk test. Secondary measures are time to engraftment, C-reactive protein, physical activity (accelerometer), grip strength, health-related quality of life (EORTC QLQ-C30 and HDC29 supplement), self-efficacy and recording of adverse events. Additionally, health service data including hospital length of stay, hospital readmissions, emergency department presentations and urgent symptom clinic presentation at 6 months will be recorded.

Discussion

This trial will provide valuable information that will inform a future definitive randomised controlled trial and implementation of prehabilitation for people receiving autologous stem cell transplant by providing data on efficacy and safety.

Trial registration

The PIRATE Trial has been approved by the Eastern Health Human Research Ethics Committee (E20/003/61055) and is funded by the Eastern Health Foundation. This trial is registered with the Australian New Zealand Clinical Trials Registry ACTRN12620000496910. Registered April 20, 2020, https://www.anzctr.org.au/Trial/Registration/TrialReview.aspx? id=379441\&isReview=true

\section{Background}

Autologous stem cell transplantation is an effective procedure that provides long-term disease control and is standard care for many haematological malignancies including multiple myeloma, lymphoma and less frequently leukaemia [1]. In selected diseases, the survival rate of patients receiving autologous stem cell transplant is up to $94 \%$ at 10 years [2]. Autologous stem cell transplants are increasingly available to patients with haematological malignancies, with over 36,000 autologous stem cell transplants completed globally each year [3].

While survival from autologous stem cell transplant is high, this procedure places patients at risk of significant short and longterm adverse effects. Patients preparing for autologous stem cell transplant receive high doses of chemotherapy and radiotherapy to eliminate tumor cells from the body. This results in a period of immunosuppression whereby people are at risk of severe infections, prolonged bed rest and immobility during a lengthy hospitalisation while awaiting bone marrow stem cell recovery. This intensive treatment frequently results in a myriad of toxic effects including sepsis, fatigue, deconditioning, peripheral neuropathy, and psychological distress causing subsequent functional decline and poor quality of life [4]. These problems may persist long after transplant with $35 \%$ of long-term transplant recipients experiencing fatigue [5]. Persistent muscle weakness, pain, cognitive impairment and distress are also common [6]. Autologous transplant recipients also have 
shorter life expectancy and higher risk of secondary cancers than the general population and experience a high rate of hospital readmission $[2,7]$.

Exercise-based rehabilitation plays an important role in mitigating the negative effects of cancer and its treatment. Guidelines recommend people with cancer participate in three times weekly aerobic and twice-weekly resistance exercise training to improve health outcomes [8]. Exercise training reduces fatigue, improves strength and quality of life in people who have received autologous stem cell transplant $[9,10]$. However, it is unknown how best to deliver exercise-based rehabilitation for people receiving autologous stem cell transplant.

Supervised exercise yields the greatest benefits for cancer survivors [8]. However, the majority of previous trials for people receiving autologous stem cell transplant have provided unsupervised training $[9,10]$. The optimal time period to provide exercise-based rehabilitation is also unknown, with most trials completed to date targeting the peri and post-transplant period [9, 10]. One trial found an 18-week supervised exercise-rehabilitation program after transplant was not cost-effective [11]. Preliminary evidence from 10 trials including both allogeneic and autologous stem cell transplant recipients participating in exercise across the treatment continuum suggests that training prior to stem cell transplant may be superior to post-transplant [10].

The addition of nutrition interventions to exercise may further enhance outcomes after autologous stem cell transplant as this group has complex nutrition needs [12]. Nutritional outcomes after transplant include poor appetite, mucositis and other gastrointestinal complications, which may lead to malnutrition [13]. Nutrition interventions provided before and after autologous stem cell transplant reduce weight-loss and hospital length of stay [14-17]. A multidisciplinary approach comprising exercise and nutrition could further optimise recovery from autologous stem cell transplant as shown in previous studies combining nutrition and exercise interventions during prehabilitation for other cancers [18].

The period before autologous stem cell transplant may be a critical period to intervene with rehabilitation (i.e. prehabilitation). Prior to stem cell transplant, patients already experience impaired physical function and quality of life [19]. Given functional performance status is positively associated with survival after transplant [20] patients preparing for transplant need to achieve a minimum level of function (Karnofsky Performance Status $\geq 70$ or Eastern Cooperative Oncology Group score $\leq 2$ ) [1]. Prehabilitation aims to build functional reserve to prepare people to cope with the physical and psychological demands of treatment. Systematic reviews have shown prehabilitation to be effective in people with other cancers receiving surgery [18]. However, limited high-quality studies have been completed for people with haematological cancer. One non-randomised feasibility study including 29 participants provided evidence a 4 to 6-week supervised exercise-rehabilitation program was safe and well accepted by patients preparing for autologous stem cell transplant [21]. Patients receiving prehabilitation required a shorter length of stay and earlier recovery of blood counts than the control group [21]. Previous studies on prehabilitation for autologous stem cell transplant have only focused on exercise, and did not consider other interventions such as nutrition support [18]. No trials have evaluated the impact of multidisciplinary prehabilitation for people preparing for autologous stem cell transplant.

\section{Aims and objectives}

The aim of this pragmatic pilot trial is to establish whether multidisciplinary prehabilitation for patients preparing for autologous stem cell transplant improves physical capacity after stem cell transplant. In addition to physical capacity, secondary efficacy outcomes will include time to engraftment, C-reactive protein levels, objective physical activity levels, grip strength, nutritional status, health-related quality of life and self-efficacy. Adverse events will also be reported as an indicator of safety. The trial will be reported consistent with the CONSORT statement for pilot and feasibility trials [22].

\section{Methods}

\section{Study design}


This is a prospective, parallel, single-blind, pragmatic, pilot randomised controlled trial to assess preliminary efficacy of multidisciplinary prehabilitation on post-autologous stem cell transplant physical capacity (See Fig. 1 for study flow chart). An 8week intervention will be completed pre-transplant with participants followed up at week 13, approximately 4 weeks after transplant and health service measures collected at week 25, approximately 12 weeks after transplant (Additional File 1).

\section{Randomisation procedures}

Eligible participants who have completed baseline measurements will be randomly allocated to the prehabilitation group or usual care control group according to an online computer-generated randomisation program, www.randomization.com, using permuted blocks. Assignments will be placed in sequentially numbered, opaque, sealed envelopes prepared prior to trial commencement by an independent researcher with no role in subject recruitment or administration of trial interventions.

\section{Setting}

The trial will be conducted in a public, tertiary cancer treatment unit that conducts approximately 30 autologous stem cell transplants annually.

\section{Patient selection and consent}

All patients referred to the haematology cancer unit for autologous stem cell transplant will be approached to participate in the trial. Potential candidates will be advised about the trial by clinic staff verbally and/or through flyers. If a patient gives permission to being contacted about the research project, they will be contacted by a member of the research team who will provide them with details of the study and arrange an outpatient appointment to provide an opportunity for questions to be clarified and to provide written informed consent.

\section{Inclusion and exclusion criteria}

Participants will be eligible if they are aged 18 years and over; have a haematological malignancy and are waitlisted for autologous stem cell transplant; and are able to give written informed consent.

Participants will be excluded if they: are medically unfit to participate in exercise as determined by a physiotherapist and/ or medical practitioner based on published recommendations [23]; have low physical performance status (Australian-modified Karnofsky Performance status (AKPS) of $<60$ or Eastern Cooperative Oncology Group (ECOG) score > 2); or have cognitive impairment precluding ability to provide written, informed consent as assessed by their treating clinician.

\section{Intervention}

All participants, whether allocated to experimental or control groups will receive usual care. Usual care will include an initial assessment with a research physiotherapist who, at this session will also provide standardised written instructions with guidelines for exercise after cancer [24-26] and a referral to a sub-acute oncology rehabilitation program after stem cell transplant. They will continue to receive their usual medical care, which may include adjuvant chemotherapy, radiotherapy, inpatient admission post-transplant, specialist, nursing and allied health outpatient appointments and visits to their general practitioner

\section{Prehabilitation intervention}

Following physiotherapy assessment and randomisation, participants allocated to the experimental group will be introduced to the gym space and have individualised exercise program designed for them based on assessment findings and goals. They will participate in twice-weekly, 60-minute exercise classes for up to 8 weeks pre-transplant following a 1-week period of physical activity monitoring (Table 1). Exercise will be supervised by a physiotherapist with cancer rehabilitation experience within the hospital gymnasium. The exercise intervention, tailored to individual patient needs, will be in a circuit format one on one or in small groups of up to 4 people. It will comprise aerobic and resistance exercise, completed at a moderate intensity (4-6 BORG rating of perceived exertion (RPE) and/or 60-80\% Heart rate (HR) maximum for aerobic exercises, 60-80\% 1-repetition maximum (for pin-loaded machines or 10-12 repetition maximum (RM) for resistance exercise) in accordance with guidelines [8]. Participants will complete a 5-minute warm up, aim to complete 25 minutes aerobic exercise, 20 minutes of resistance 
exercise, 5-minutes of flexibility or balance training (as indicated) and 5-minute cool down. Exercise intensity during aerobic exercise will be monitored by the physiotherapist using the modified BORG scale and using a portable heart rate monitor. During weeks 1 and 2, participants will aim to exercise at a BORG RPE of 3 (moderate), and by week 8 participants will aim to exercise at a 5-6 (hard) on the scale. For resistance exercise, weights will be progressed once a participant is achieving 2 to 3 sets of 1012 repetitions. Resistance exercise may include upper and lower body resistance exercise such as squats, step ups, free weights, wall push-ups, free weights, resistance exercise bands, pin-loaded machines (lateral pull down, leg press, chest press). Aerobic exercise may include treadmill, stationary cycle, or an arm ergometer. Various upper and lower body stretches and balance exercise will be incorporated into the program as required. Participants in the prehabilitation group will be encouraged to complete an additional once-weekly 30-minute aerobic exercise training session at home to comply with exercise guidelines for people with cancer [8]. Patients will be also be instructed to remain as active as possible and avoid prolonged periods of sitting and lying in the period following stem cell transplant.

A dietitian will provide written information and fortnightly phone calls over the 8-week period (up to 4 sessions) to patients offering tailored medical nutrition therapy based on initial dietetic consultation. The focus will be on supporting oral intake and maintaining nutritional status during the prehabilitation period. Guidelines for managing potential gastrointestinal symptoms during the post-transplantation period will also be provided [13].

The fidelity of the intervention will be monitored by recording the content of exercise and nutrition sessions in logbooks, recording the number and duration of completed sessions with the physiotherapist and dietitian and monthly meetings with clinical staff.

\section{Control group}

Participants randomised to the control group will receive their usual medical care and receive standardised written instructions with guidelines for exercise after cancer from the physiotherapist [24-26]. 


\begin{tabular}{|c|c|c|c|}
\hline & \multicolumn{2}{|l|}{ Experimental Group } & Control Group \\
\hline Brief Name & \multicolumn{2}{|l|}{ Prehabilitation } & Usual Care \\
\hline Why & \multicolumn{2}{|c|}{$\begin{array}{l}\text { Prehabilitation may build functional } \\
\text { reserves to better cope with } \\
\text { transplant }\end{array}$} & Pragmatic trial design \\
\hline \multirow[t]{6}{*}{$\begin{array}{l}\text { What: } \\
\text { Materials }\end{array}$} & \multicolumn{2}{|c|}{$\begin{array}{l}\text { - Participants will receive access to } \\
\text { the hospital gymnasium: }\end{array}$} & $\begin{array}{l}\text { - Participants will receive 1) standardised written handout exercise 2) } \\
\text { referral to Oncology Rehabilitation Program post-transplant }\end{array}$ \\
\hline & \multicolumn{2}{|l|}{ - Free weights } & \multirow{5}{*}{$\begin{array}{l}\text { - Usual care also includes usual medical care which may include } \\
\text { adjuvant chemotherapy, radiotherapy, inpatient admission post- } \\
\text { transplant, specialist, nursing and allied health outpatient } \\
\text { appointments, visits to their general practitioner and general advice } \\
\text { from their medical team to remain active and eat a healthy diet. }\end{array}$} \\
\hline & \multicolumn{2}{|c|}{ - Resistance exercise bands } & \\
\hline & \multicolumn{2}{|c|}{$\begin{array}{l}\text { - Pin-loaded machines (lateral pull } \\
\text { down, leg press, chest press) }\end{array}$} & \\
\hline & \multicolumn{2}{|c|}{$\begin{array}{l}\text { - Participants will receive 1) } \\
\text { standardised written handout } \\
\text { exercise 2) standardised written } \\
\text { handout nutrition } 3 \text { ) referral to } \\
\text { Oncology Rehabilitation Program } \\
\text { post-transplant }\end{array}$} & \\
\hline & \multicolumn{2}{|c|}{$\begin{array}{l}\text { - Participants will receive usual } \\
\text { hospital care }\end{array}$} & \\
\hline \multicolumn{4}{|l|}{$\begin{array}{l}\text { What } \\
\text { Procedures }\end{array}$} \\
\hline Provider & \multicolumn{2}{|c|}{$\begin{array}{l}\text { Physiotherapist and dietitian with } \\
\text { oncology experience provided by the } \\
\text { hospital }\end{array}$} & Usual hospital staff \\
\hline How & \multicolumn{2}{|l|}{ Face to face sessions } & No intervention \\
\hline Where & \multicolumn{2}{|l|}{ Hospital gymnasium } & No intervention \\
\hline $\begin{array}{l}\text { When/How } \\
\text { much }\end{array}$ & Exercise & Nutrition & \multirow[t]{8}{*}{ - Standardised written advice about exercise and cancer guidelines } \\
\hline Intensity & \multicolumn{2}{|l|}{$\begin{array}{l}\text { Moderate (BORG 4- } \\
6 \text { ) }\end{array}$} & \\
\hline Frequency & \multicolumn{2}{|l|}{$\begin{array}{l}60-80 \% \mathrm{HR} \\
\text { maximum }\end{array}$} & \\
\hline $\begin{array}{l}\text { Session } \\
\text { time }\end{array}$ & \multicolumn{2}{|l|}{$60-80 \%$ 1-RM } & \\
\hline \multirow{4}{*}{$\begin{array}{l}\text { Overall } \\
\text { duration }\end{array}$} & $2 x$ weekly in centre & Fortnightly & \\
\hline & $1 \mathrm{X}$ weekly at home & & \\
\hline & 60 minutes & $\begin{array}{l}30 \\
\text { minutes }\end{array}$ & \\
\hline & \multicolumn{2}{|l|}{8 weeks } & \\
\hline Tailoring & \multicolumn{2}{|c|}{$\begin{array}{l}\text { - Individualised exercise program } \\
\text { and nutrition advice based on initial } \\
\text { consultation and goals }\end{array}$} & - None \\
\hline
\end{tabular}




\begin{tabular}{|lll|}
\hline & Experimental Group & Control Group \\
\hline Trial & $\begin{array}{l}\text { - Staff with a background in } \\
\text { oncology physiotherapy and } \\
\text { dietetics who had prior formal } \\
\text { training were employed by the } \\
\text { hospital to provide the intervention }\end{array}$ & $\begin{array}{l}\text { - Participants will be asked if they participated in any physical activity } \\
\text { or nutrition intervention during the usual care period. }\end{array}$ \\
& - Exercise log-books will be \\
completed and reviewed by research \\
staff. Estimated 1-RM testing will be \\
reassessed at week 4 to ensure \\
sufficient strength training stimulus. \\
- Nutrition log-books will be \\
completed and reviewed by research \\
staff. \\
- Records of the number and \\
duration of completed sessions. \\
- Monthly meetings with clinical \\
research staff
\end{tabular}

\section{Study outcomes}

Participants will complete an assessment of physical capacity, physical activity, inflammation, time to engraftment, healthrelated quality of life, self-efficacy, nutritional status and muscle strength at baseline and after the intervention phase at week 8 (pre-transplant) and week 13 (post-transplant infusion). Hospital length of stay will be recorded at week 13, and emergency department, Symptom and Urgent Review Clinic (SURC) presentations and hospital readmissions will be recorded at week 25 from hospital data bases. A trained allied health clinician blind to group allocation will complete baseline and follow-up assessments to ensure blinding of outcome measures. Peripheral blood count analysis and blood product use will be completed by an independent assessor, blinded to group allocation. Primary and secondary outcomes are outlined in Table 2.

Adverse events related to the intervention as defined by the World Health Organization [27] will be documented to report safety of the intervention. The event may or may not be related to the intervention, but it occurs while the person is participating in the intervention phase (during prehabilitation) of the trial. Adverse events will be categorised as minor adverse events or serious adverse events. A minor adverse event is defined as an incident that occurs

while participating in the intervention that results in no injury or minor injury (e.g. fatigue, exacerbation of pre-existing musculoskeletal pain) that requires none or minor medical intervention. A serious adverse event is defined as an incident that occurs while the person is participating in the intervention that results in death, serious injury or re-hospitalisation. 
Table 2

Primary and secondary outcomes

\begin{tabular}{|c|c|c|}
\hline $\begin{array}{l}\text { Primary } \\
\text { outcome }\end{array}$ & Measure/source & Definition \\
\hline $\begin{array}{l}\text { Physical } \\
\text { Capacity }\end{array}$ & $\begin{array}{l}\text { 6-Minute Walk } \\
\text { Test }\end{array}$ & $\begin{array}{l}\text { Change in walk distance }(\mathrm{m}) \text { pre-post intervention. Primary endpoint is } 4 \text { weeks post- } \\
\text { transplant infusion }\end{array}$ \\
\hline \multicolumn{3}{|l|}{$\begin{array}{l}\text { Secondary } \\
\text { outcomes }\end{array}$} \\
\hline $\begin{array}{l}\text { Physical } \\
\text { Activity }\end{array}$ & ActivPal $^{T M}$ & $\begin{array}{l}\text { Change in time spent walking, standing, sitting, sit-to-stand transitions, and step count } \\
\text { pre and post intervention. Participants will wear the activity monitor continuously or } 8 \\
\text { consecutive days. Only complete } 24 \text {-hour recording days will be included for analysis. } \\
\text { However, as monitors may need to be removed for the purpose of swimming or bathing, } \\
\text { evidence of non-wear matching with an activity logbook will still be included. }\end{array}$ \\
\hline $\begin{array}{l}\text { Health- } \\
\text { Related } \\
\text { Quality of } \\
\text { Life }\end{array}$ & $\begin{array}{l}\text { EORTC-QLQ C30 } \\
\text { and EORTC } \\
\text { QLQ-HDC29 }\end{array}$ & $\begin{array}{l}\text { Change of score on validated quality of life questionnaires QLQ-C30 and HDC29 pre and } \\
\text { post intervention. }\end{array}$ \\
\hline $\begin{array}{l}\text { Self-efficacy } \\
\text { for physical } \\
\text { activity }\end{array}$ & $\begin{array}{l}\text { Questionnaire } \\
\text { developed using } \\
\text { HAPA } \\
\text { (Additional file } \\
\text { 2) }\end{array}$ & $\begin{array}{l}\text { Change of score on self-efficacy questionnaire for physical activity pre and post } \\
\text { intervention. }\end{array}$ \\
\hline $\begin{array}{l}\text { Nutritional } \\
\text { status }\end{array}$ & PG-SGA & Change of score on validated PG-SGA pre and post intervention. \\
\hline $\begin{array}{l}\text { Handgrip } \\
\text { strength }\end{array}$ & $\begin{array}{l}\text { Jamar handgrip } \\
\text { dynamometer }\end{array}$ & $\begin{array}{l}\text { Change in handgrip strength }(\mathrm{kg}) \text { pre and post intervention assessed using the best } \\
\text { measure of } 6 \text { trials ( } 3 \text { in each hand). }\end{array}$ \\
\hline Inflammation & $\begin{array}{l}\text { C-Reactive } \\
\text { Protein }\end{array}$ & $\begin{array}{l}\text { Change in CRP levels pre and post intervention. Patients will be instructed not to } \\
\text { undertake moderate to vigorous intensity exercise for } 24 \text { hours prior to collection. }\end{array}$ \\
\hline $\begin{array}{l}\text { Stem cell } \\
\text { engraftment }\end{array}$ & $\begin{array}{l}\text { Routine blood } \\
\text { samples }\end{array}$ & $\begin{array}{l}\text { Number of days from transplant to engraftment. Engraftment is defined as neutrophils } \\
>0.5 \times 10^{9} / \mathrm{L} \text { for three days without support and platelets }>50 \times 10^{9} / \mathrm{L} \text { for five days } \\
\text { without transfusion. }\end{array}$ \\
\hline $\begin{array}{l}\text { Hospital } \\
\text { length of } \\
\text { stay }\end{array}$ & $\begin{array}{l}\text { Hospital } \\
\text { database }\end{array}$ & $\begin{array}{l}\text { Days that the patient is in the hospital from day of stem cell infusion to day of } \\
\text { discharge. }\end{array}$ \\
\hline $\begin{array}{l}\text { ED/SURC } \\
\text { presentations }\end{array}$ & $\begin{array}{l}\text { Hospital } \\
\text { database and } \\
\text { electronic } \\
\text { medical record }\end{array}$ & $\begin{array}{l}\text { Number of emergency department presentations and Symptom and Urgent Review } \\
\text { Clinic (SURC) presentations over three months after discharge from the autologous } \\
\text { stem cell transplant admission. }\end{array}$ \\
\hline $\begin{array}{l}\text { Hospital re- } \\
\text { admissions }\end{array}$ & $\begin{array}{l}\text { Hospital } \\
\text { database }\end{array}$ & $\begin{array}{l}\text { Number of hospital readmissions over } 3 \text { months after discharge from the autologous } \\
\text { stem cell transplant admission and associated inpatient days with each readmission }\end{array}$ \\
\hline
\end{tabular}

Reasons for non-participation in an exercise session or non-completion of the program will be recorded (e.g. pain, fatigue, unwell). Complications related to the stem cell transplant procedure will also reported for each group (e.g. infection, bleeding, mucositis, parental nutrition requirements, intensive care support).

Other routinely collected data will be used to describe the sample including age, gender, cancer type, cancer stage, treatment regimens, co-morbidities, functional performance status (AKPS and ECOG), body mass index.

\section{Sample size estimation}

To gain a preliminary understanding of the effect of the intervention on clinical outcomes, a sample size sufficient to detect a clinically significant between-group difference in physical capacity of $53 \mathrm{~m}$, assuming a large effect size of 1.3 at a power of 0.8 
and an alpha level of 0.05 , will be sought. It was calculated a sample of 22 patients waitlisted for autologous stem cell transplant at the health service would be adequate. No minimal clinically significant difference has been calculated in patients receiving autologous stem cell transplant therefore it was estimated to be $41 \mathrm{~m}$ based on half a standard deviation [28] of scores of a mixed cohort of cancer survivors [29]. Approximately 30 people are treated with autologous stem cell transplant at the health service annually. Our sample size represents a recruitment rate of $75 \%$ which is similar to a recently completed cancer rehabilitation trial at the health service [30].

\section{Statistical analysis}

The primary outcome (physical capacity at 4-weeks post-transplant) will be analysed using linear mixed effects models. Modelling will account for variation in baseline values. This method accounts for within-participant dependence of observations over time, and for missing data, allowing some participants to have missing observations at certain time points. If more than $5 \%$ of data are missing, a multiple imputation process will be used, providing the assumption data are missing at random is met. A similar approach will be used for analysis of continuous secondary outcomes collected longitudinally. The time spent in moderate to vigorous physical activity will be estimated using a cut-off of 100 steps/minute for moderate intensity physical activity [31]. The proportion of participants meeting physical activity guidelines will be described and compared between groups with a risk ratio. The number of emergency department, SURC presentations and hospital admissions will be reported as an incidence rate ratio using a negative binomial regression model. To avoid bias and to maximize the randomisation process, all available data will be analysed according to allocation (intention to treat analysis), regardless of compliance.

\section{Discussion}

This trial aims to capitalise on the 'teachable moment' of cancer diagnosis to improve physical capacity and expedite the recovery of patients undergoing autologous stem cell transplant. The benefits of rehabilitation for people with cancer, including exercise and nutrition interventions, are well documented. However, rehabilitation interventions are often not considered until treatment completion [32] at which stage impairment and further co-morbidity has developed. Early intervention provided by prehabilitation may mitigate the extensive treatment burden of autologous stem cell transplant and better prepare people physically and mentally for their lengthy recovery. If this trial finds evidence of efficacy and safety it may transform the stem cell transplant clinical pathway.

A strength of this trial is the inclusion of health service outcomes such as length of stay, emergency department presentations and hospital readmissions. Access to multidisciplinary cancer rehabilitation services, including prehabilitation, is poor [33]. Results relating to these endpoints which are valued by hospital administrators and policy makers may help drive future implementation of prehabilitation in health services to improve patient access. Preliminary evidence suggests that rehabilitation interventions conducted in early phases of cancer treatment may deliver cost-savings. For example, trials of prehabilitation for people receiving lung cancer surgery demonstrate reductions in costly hospital stays of 4 days and complications by $67 \%$ [34]. A trial of rehabilitation during chemotherapy for women with breast cancer also demonstrated cost savings [35]. In comparison, a trial of exercise after autologous stem cell transplant was not cost effective [11]. Data relating to health service benefits will guide decision making to see prehabilitation translated to practice.

Another strength is the multidisciplinary nature of the trial. Two trials of prehabilitation for autologous stem cell transplant have recently been registered $[36,37]$ however, these both focus on exercise alone. As people undergoing autologous stem cell transplant are at high risk of malnutrition and loss of muscle mass, the inclusion of nutrition intervention is of upmost importance. A recent systematic review identified five studies where prehabilitation included a nutrition intervention prior to surgery for cancer [18]. Three of these studies included nutrition only interventions [38-40], while a combined exercise/nutrition intervention was integral to two studies $[38,41]$. Nutrition counselling in addition to a range of interventions (e.g. the addition of supplemental arginine, whey protein and other dietary modifications) were the focus of the intervention groups. Significant improvements in functional measures arose from these nutrition interventions, including in physical functioning and postoperative symptoms. The value of multimodal prehabilitation has been recognised in a surgical context $[18,42]$ and this could extend to pre-transplant cohorts. 
One possible limitation of this trial is the inclusion of face to face therapy. This trial was approved and registered prior to the full realisation of the COVID-19 pandemic. It is currently on hold until face to face consultations can resume. The safety risks of face to face rehabilitation associated with the pandemic, especially in this particularly vulnerable group has led to a surge in telehealth to enable critical supportive care delivered remotely. Cancer survivors are accepting of telehealth describing it as convenient, reassuring and minimising treatment burden [43]. Early trials of telehealth for delivering rehabilitation interventions to cancer survivors are also promising, but have been largely limited to education and coaching delivered via phone [44, 45]. Oncology rehabilitation trials and programs around the world have had to alter their protocols to include novel solutions such as video conferencing, digital exercise programs and remote monitoring to overcome the challenges associated with COVID-19 [46]. In some parts of Australia, there has already been some easing of COVID restrictions allowing community-based exercise.

Therefore, we anticipate being able to commence this trial in early 2021. However, should the need arise, important lessons have been learnt in adapting to telehealth that can be adopted for this trial. Another limitation of this trial is the small sample size, which may be underpowered to demonstrate clinical effect. Results may also not be generalisable to all settings that conduct autologous stem cell transplant. However, it is acknowledged this is a pilot and results will inform future robust trials on a larger scale.

Prehabilitation is an important area of oncology supportive care research that has potential to challenge current care delivery. This trial may optimise patient and health service outcomes and aid efforts to see prehabilitation integrated as standard care for people with haematological malignancies.

\section{Declarations}

\section{Ethics approval:}

The PIRATE Trial has been approved by the Eastern Health Human Research Ethics Committee (E20/003/61055)

\section{Availability of data and materials:}

This is the study protocol of the study which has not yet commenced therefore no data are available. We intend to publish our results in peer reviewed journals and also at national and international conferences.

\section{Competing interests:}

The authors declare that they have no competing interests.

\section{Funding:}

This trial was funded by a grant from the Eastern Health Foundation. The foundation was not involved in design of the study and collection, analysis, and interpretation of data or in writing the manuscript.

\section{Authors' contributions:}

AD prepared the first draft of the manuscript. All authors critically revised and provided input to subsequent drafts and read and approved the final manuscript

\section{Acknowledgements:}

We would like to acknowledge the haematology and oncology rehabilitation staff at Eastern Health who will be supporting recruitment for this trial. 


\section{References}

1. Hamadani M. Autologous hematopoietic cell transplantation: An update for clinicians. Ann Med 2014;46: 619-32.

2. Majhail NS, Rizzo JD. Surviving the cure: long term followup of hematopoietic cell transplant recipients. Bone Marrow Transplant 2013;48: 1145-51.

3. Niederwieser D, Baldomero H, Szer J, Gratwohl M, Aljurf M, Atsuta Y et al. Hematopoietic stem cell transplantation activity worldwide in 2012 and a SWOT analysis of the Worldwide Network for Blood and Marrow Transplantation Group including the global survey. Bone marrow Transplant 2016;51: 778-85.

4. Steinberg A, Asher A, Bailey C, Fu JB.The role of physical rehabilitation in stem cell transplantation patients. Support Care Cancer 2015; 23: 2447-60.

5. Gielissen MF, Schattenberg AV, Verhagen CA, Rinkes MJ, Bremmers ME, Bleijenberg G. Experience of severe fatigue in longterm survivors of stem cell transplantation. Bone Marrow Transplant 2007;39:595-603.

6. Syrjala KL, Martin PJ, Lee SJ. Delivering care to long-term adult survivors of hematopoietic cell transplantation. J Clin Oncol 2012;30:3746-51.

7. Fu JB, Lee J, Smith DW, Guo Y, Bruera E. Return to primary service among bone marrow transplant rehabilitation inpatients: an index for predicting outcomes. Arch Phys Med Rehab, 2013;94: 356-61.

8. Campbell KL, Winters-Stone KM, Wiskemann J, May AM, Schwartz AL, Courneya KS et al. Exercise guidelines for cancer survivors: consensus statement from international multidisciplinary roundtable. Med Sci Sports Exerc 2019;51:2375-90.

9. Jarden M, Baadsgaard MT, Hovgaard DJ, Boesen E, Adamsen L. A randomized trial on the effect of a multimodal intervention on physical capacity, functional performance and quality of life in adult patients undergoing allogeneic SCT. Bone Marrow Transplant 2009;43: 725-37.

10. Liang Y, Zhou M, Wang F, Wu Z. Exercise for physical fitness, fatigue and quality of life of patients undergoing hematopoietic stem cell transplantation: a meta-analysis of randomized controlled trials. Jpn J Clin Oncol 2018;48: 104657.

11. van Dongen JM., Persoon S, Jongeneel G, Bosmans JE, Kersten MJ, Brug J et al. Long-term effectiveness and costeffectiveness of an 18-week supervised exercise program in patients treated with autologous stem cell transplantation: results from the EXIST study. J Cancer Surviv 2019;13: 558-69.

12. Hung YC, Bauer J, Horsley P, Waterhouse M, Bashford J, Isenring E. Changes in nutritional status, body composition, quality of life, and physical activity levels of cancer patients undergoing autologous peripheral blood stem cell transplantation. Support Care Cancer 2013; 21: 1579-86.

13. Murray, SM, Pindoria S. Nutrition support for bone marrow transplant patients. Cochrane Database Syst. Rev. 2017. 3:CD002920-CD002920.

14. Andersen S, Brown T, Kennedy G, Banks M. Implementation of an evidenced based nutrition support pathway for haematopoietic progenitor cell transplant patients. Clin Nutr 2015;34: 536-40.

15. Atkins L, Steer B, Ray H, Kiss N. Implementing and sustaining an evidence-based nutrition service in a haematology unit for autologous stem cell transplant patients. Support Care Cancer, 2019;27:951-58.

16. Hagiwara S, Mori T, Tuchiya H, Sato S, Higa M, Watahiki M, et al. Multidisciplinary nutritional support for autologous hematopoietic stem cell transplantation: a cost-benefit analysis. Nutrition 2011;27:1112-7.

17. Hung YC, Bauer JD, Horsely P, Coll J, Bashford J, Isenring EA .Telephone-delivered nutrition and exercise counselling after auto-SCT: a pilot, randomised controlled trial. Bone Marrow Transplant 2014;49:786-92.

18. Faithfull S, Turner L, Poole K, Joy M, Manders R, Weprin J, Winters-Stone K et al. Prehabilitation for adults diagnosed with cancer: A systematic review of long-term physical function, nutrition and patient-reported outcomes. Eur J Cancer Care 2019;28:e13023.

19. Morishita S, Kaida K, Ikegame K, Yoshihara S, Taniguchi K, Okada M et al. Impaired physiological function and healthrelated QOL in patients before hematopoietic stem-cell transplantation. Support Care Cancer 2012;20:821-9. 
20. Rotta M, Storer BE, Sahebi F, Shizuru JA, Bruno B, Lange T et al., Long-term outcome of patients with multiple myeloma after autologous hematopoietic cell transplantation and nonmyeloablative allografting. Blood 2009;113:3383-91.

21. van Haren I, Staal JB, Potting CM, Atsma F, Hoogeboom TJ, Blijlevens eNMA et al. Physical exercise prior to hematopoietic stem cell transplantation: A feasibility study. Physiother Theory Pract 2018;34:747-56.

22. Eldridge SM, Chan CL, Campbell MJ, Bond CM, Hopewell S, Thabane L et al. CONSORT 2010 statement: extension to randomised pilot and feasibility trials. BMJ 2016; 355:i5239.

23. Santa-Mina D, Langelier D, Adams SC, Alibhai SMH, Chasen M, Campbell KL et al. Exercise as part of routine cancer care. Lancet Oncol 2018;19:e433-36.

24. American College of Sports Medicine, Exercise is Medicine. Being Active When You Have Cancer. 2019. https://www.exerciseismedicine.org/assets/page_documents/EIM_Rx\%20for\%20Health_Cancer.pdf. Accessed 31 July 2020

25. American College of Sports Medicine, Exercise is Medicine. Sit Less, Move More. 2019. https://www.exerciseismedicine.org/assets/page_documents/EIM_Rx\%20for\%20Health_Sit\%20Less\%20Move\%20More.pdf. Accessed 31 July 2020

26. American College of Sports Medicine, Exercise is Medicine. Moving Through Cancer. 2019 https://www.exerciseismedicine.org/assets/page_documents/EIM\%20moving\%20through\%20cancer\%20form\%20web.pdf. Accessed 31 July 2020

27. World Health Organisation, World alliance for patient safety : WHO draft guidelines for adverse event reporting and learning systems: from information to action. 2005, World Health Organization: Geneva.

28. Norman GR, Sloan JA, Wyrwich KW, Interpretation of changes in health-related quality of life: the remarkable universality of half a standard deviation. Med Care 2003;41:582-92.

29. Schmidt K, Vogt L, Thiel C, Jäger E, Banzer W. Validity of the six-minute walk test in cancer patients. Int J Sports Med 2013;34:631-6.

30. Dennett AM, Shields N, Peiris CL, Prendergast LA, Parente P, Taylor NF. Motivational interviewing added to oncology rehabilitation did not improve moderate-intensity physical activity in cancer survivors: a randomised trial. J Physiother 2018;64:255-63.

31. Abel M, Hannon J, Mullineaux D, Beighle A. Determination of step rate thresholds corresponding to physical activity intensity classifications in adults. J Phys Act Health 2011;8:45-51.

32. Courneya KS, Friedenreich CM. Physical activity and cancer control. Semin Oncol Nurs 2007;23:242-52.

33. Dennett AM, Peiris CL, Shields N, Morgan D, Taylor NF. Exercise therapy in oncology rehabilitation in Australia: A mixedmethods study. Asia Pac J Clin Oncol 2017;13:e515-27.

34. Cavalheri V, Granger C. Preoperative exercise training for patients with non-small cell lung cancer. Cochrane Database Syst Rev 2017;6:Cd012020.

35. van Waart H, van Dongen JM, van Harten WH, Stuiver MM, Huijsmans R, Hellendoorn-van Vreeswijk JAJH et al. Cost-utility and cost-effectiveness of physical exercise during adjuvant chemotherapy. Eur J Health Econ 2018; 19:893-904.

36. National Institutes of Health,U.S. National Library of Medicine, ClinicalTrials.gov. Impact of Prehabilitation in Oncology Via Exercise- Bone Marrow Transplant (IMPROVE-BMT). 2020 https://clinicaltrials.gov/ct2/show/NCT03886909? term=prehabilitation\&cond=bone+marrow+transplant\&draw=2\&rank=1. Accessed 31 July 2020.

37. National Institutes of Health, U.S. National Library of Medicine, ClinicalTrials.gov. Feasibility of Pre-Transplant Exercise (Prehabilitation) for Multiple Myeloma Patients Awaiting Autologous Stem Cell Transplantation 2020 https://clinicaltrials.gov/ct2/show/NCT03135925?

term=exercise\&cond=autologous+stem+cell+transplant\&draw=4\&rank=3. Accessed 31 July 2020.

38. Gillis C, Li C, Lee L, Awasthi R, Augustin B, Gamsa A, et al. Prehabilitation versus rehabilitation: a randomized control trial in patients undergoing colorectal resection for cancer. Anesthesiology 2014;121:937-47.

39. Moriya T, Fukatsu K, Okamoto K, Shinto E, Ueno H, Hasel K et al. Effects of preoperative use of an immune-enhancing diet on postoperative complications and long-term outcome: a randomized clinical trial in colorectal cancer surgery in Japanese patients. Clin Nutr 2014;33:S247. 
40. van Bokhorst-De Van Der Schueren MA, Quak JJ, von Blomberg-van der Flier BM, Kuik DJ, Langendoen SI, Snow GB, et al. Effect of perioperative nutrition, with and without arginine supplementation, on nutritional status, immune function, postoperative morbidity, and survival in severely malnourished head and neck cancer patients. Am J Clin Nutr 2001;73:32332.

41. Li C, Carli F, Lee L, Charlebois P, Stein B, Liberman AS, et al. Impact of a trimodal prehabilitation program on functional recovery after colorectal cancer surgery: a pilot study. Surg Endosc 2013;27:1072-82.

42. Bolshinsky V, Li, Ismail H, Burbury K, Riedel B, Heriot A. Multimodal prehabilitation programs as a bundle of care in gastrointestinal cancer surgery: a systematic review. Dis Colon Rectum 2018;61:124-38.

43. Cox A, Lucas G, Marcu A, Piano M, Grosvenor W, Mold F et al. Cancer survivors' experience with telehealth: a systematic review and thematic synthesis. J Med Internet Res 2017;19:e11.

44. Cheville AL, Moynihan T, Herrin J, Loprinzi C, Kroenke K. Effect of collaborative telerehabilitation on functional impairment and pain among patients with advanced-stage cancer: a randomized clinical trial. JAMA Oncol;2019. 5: 644-52.

45. Ward E, Burns C., Wall L, COSA Teleoncology Guidelines Working Group. What models of care for teleoncology are available to allied health services? In: COSA Teleoncology Guidelines Working Group. Clinical practice guidelines for teleoncology. 2016, Cancer Council Australia: Sydney.

46. Newton RU, Hart NH, Clay T. Keeping patients with cancer exercising in the age of COVID-19. JCO Oncology Practice. 2020:OP.20.00210. (Epub ahead of print)

\section{Figures}




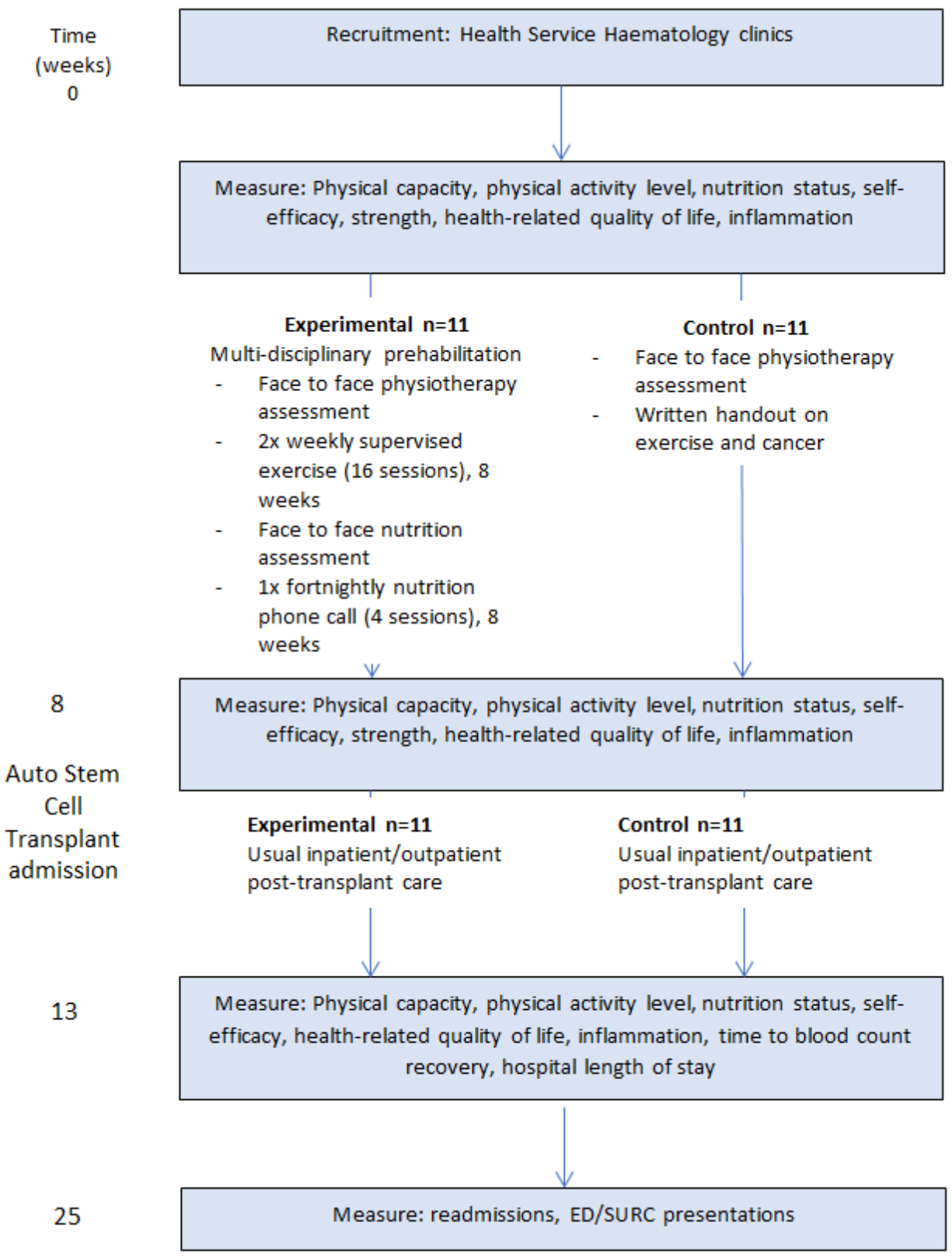

\section{Figure 1}

Trial design

\section{Supplementary Files}

This is a list of supplementary files associated with this preprint. Click to download.

- supplement4.docx

- supplement5.doc

- supplement6.doc 